\title{
O PROFESSOR LICENCIADO NA EDUCAÇÃO PROFISSIONAL: QUAIS OS SABERES DOCENTES QUE ALICERÇAM SEU TRABALHO?
}

\author{
J. K. C MORAIS E A. L. S HENRIQUE \\ Instituto Federal de Educação, Ciência e Tecnologia do Rio Grande do Norte \\ kaioifrn@gmail.com*
}

Artigo submetido em outubro/2014 e aceito em dezembro/2014

DOI: $10.15628 /$ rbept.2014.3499

\section{RESUMO}

Situando em meio as discussões acerca da formação e saberes docentes necessários ao trabalho do professor na Educação Profissional (EP), esse artigo surge como um recorte inicial de um estudo maior que visa analisar os saberes docentes necessários ao fazer do professor de Biologia que trabalha no Ensino Médio Integrado à Educação Profissional. Em meio a isso, esse artigo especificamente, tem como objetivo analisar os saberes docentes dos professores licenciados que atuam na EP. Para isso, consultou-se os estudos de Moura (2008), Machado (2008), Silva Júnior e Garíglio (2014) e Imbernón (2009) para alcançar tal intento, o que configurou essa pesquisa enquanto bibliográfica, do tipo qualitativa. Os resultados mostram que o professor licenciado vivencia uma formação inicial em cursos de licenciatura que deveria proporcionar a construção de determinados saberes da docência. Entretanto, percebese que nas licenciaturas brasileiras, os futuros professores não conseguem construir de forma sólida e articulada esses saberes, o que compromete seu trabalho em sala de aula, sobretudo em situações e modalidades de ensino específicas, como é o caso da EP. Posto isso, alguns autores enumeram alguns saberes docentes específicos da EP: saber técnico, saber pedagógico e saber da pesquisa.

PALAVRAS-CHAVE: Educação Profissional, Formação de Professores, Trabalho Docente, Saberes docentes.

\section{LICENSED TEACHER TO PROFESSIONAL EDUCATION: WHAT KNOWLEDGES ARE REQUIRED?}

\begin{abstract}
Situated in the middle of discussions on training and teacher's work in Professional Education (EP), this article appears as an initial cut of a larger study to analyze the teaching knowledge needed to do the Biology teacher working in High School integrated into the Professional Education. This article specifically analyze the teaching knowledge of teachers working in the EP. Consultation studies of Moura (2008), Machado (2008), Silva Junior and Gariglio (2014) and Imbernon (2009) to accomplish this goal, so this research is bibliography, the qualitative
\end{abstract}

type. The results show that the teacher undergoes an initial training in teacher training courses that should help in their training, but realizes that the future teachers can not build a solid and articulated this knowledge, which compromises their work in the classroom class, particularly in specific teaching situations and conditions, such as EP. That said, some authors cite some specific knowledge of teachers EP: technical knowledge, pedagogical knowledge and know the research 


\section{INTRODUÇÃO}

$\mathrm{Na}$ atualidade percebe-se que o trabalho do professor é extremamente relevante no contexto da educação brasileira, tendo em vista que ele é o principal agente do processo de ensino e aprendizagem dos cidadãos. Nesse sentido, espera-se que o docente possibilite aos estudantes os pressupostos necessários para uma reflexão em torno dos conhecimentos historicamente construídos e, além disso, forme para que eles tenham uma visão crítica sobre o contexto social, cultural, político e econômico no qual estão inseridos.

Nessa perspectiva, por meio do seu trabalho, o professor contribui para a formação de sujeitos que tenham conhecimentos técnico-científicos, condição necessária para a produção material da vida, que compreendam as relações sociais e de produção numa perspectiva sóciohistórico-crítica e que tenham compromisso ético-político com os interesses da classe-que-vivedo-trabalho (ANTUNES, 2009) e, em consequência, de sua formação enquanto cidadãos emancipados (MOURA, 2013).

De acordo com Almeida e Lacerda (2015), o professor que tenha como objetivo essa perspectiva, deve assumir a responsabilidade ético-política em seu fazer educativo, compreendendo a educação como possibilidade de transformação das pessoas bem como da própria sociedade. Apesar disso, os autores lembram que este tipo de educação no Brasil encontrase distante de sua efetividade, uma vez que a educação brasileira foi ao longo da história um instrumento a serviço da manutenção do poder. É por essa questão que se construiu historicamente um povo tão submetido e tão resignado diante de tantas injustiças e violências estruturais (ALMEIDA; LACERDA, 2015, p. 145).

Em direção contrária a esse modelo, defendemos uma formação em que os sujeitos alcancem autonomia e emancipação, de modo que possam atuar na perspectiva da transformação social orientada ao atendimento dos interesses e necessidades das classes trabalhadoras. Para alcançar esse intento, é necessária uma formação integrando as dimensões do trabalho, no sentido ontológico, ciência, tecnologia e cultura, na perspectiva da formação humana integral emancipatória (MOURA, 2013).

Para alcançar tal objetivo, precisamos repensar o próprio contexto educacional brasileiro, tendo em vista que esse sempre esteve submetido aos interesses hegemônicos do capital. 0 professor, nesse cenário, desenvolve uma função primordial, uma vez que ele é o agente diretamente envolvido no processo educacional formativo das novas gerações. Sendo assim, a sua própria formação docente surge como tema de interesse nessa busca para uma educação de caráter emancipatório.

Compreende-se, portanto, que o trabalho do professor vai além de transmitir conteúdos prontos historicamente construídos, mas problematizar a sociedade no intuito de ir ao encontro de uma transformação da realidade da sociedade capitalista neoliberal atual. Dessa forma, pesquisas que sigam a direção de problematizar o trabalho do professor são relevantes, uma vez que podem agir como força impulsionadora para o objetivo ora citado.

Dessa forma, enquanto pesquisadores do Programa de Pós-Graduação em Educação Profissional (PPGEP) do Instituto Federal de Educação, Ciência e Tecnologia do Rio Grande do Norte (IFRN), este artigo surge como um recorte inicial de uma discussão maior e, contraditoriamente, mais específico sobre o trabalho dos professores de Biologia que atuam na Educação Profissional. 
Com o intuito de aproximar as leituras sobre a formação e saberes dos professores na EP, o presente artigo surge como um redirecionamento do projeto de dissertação submetido ao PPGEP. Neste momento, comenta-se a respeito da formação e os saberes docente dos professores que trabalham na EP, com ênfase no caso dos sujeitos licenciados em disciplinas da educação básica, como por exemplo, História, Química, Física e Biologia por exemplo.

Logo, este recorte inicial deve contribuir no sentido de maturar o objeto de estudo proposto para a dissertação. Sendo assim, objetiva-se, por meio dessa discussão teórica, tratar sobre a formação de professores na EP e os saberes docentes mobilizados por estes em seu fazer cotidiano. Mediante isso, surge alguns questionamentos iniciais, dentre eles: Como são formados os professores licenciados que trabalham na EP? Qual a função do professor licenciado na EP? Que saberes docentes são necessários ao trabalho desse professor licenciado?

Com base no objetivo proposto e nas questões norteadoras, decidiu-se por uma pesquisa bibliografia a partir dos seguintes autores: Moura (2008), Machado (2008), Silva Júnior e Garíglio (2014), Imbernón (2009), Pereira (2006) dentre outros autores que discorrem sobre formação e saberes docentes e, mais especificamente, os saberes dos professores que trabalham na EP.

Além deste tópico inicial, faz-se, no segundo tópico, uma breve discussão sobre a formação e os saberes docente dos professores. No terceiro momento, adentra-se especificamente nas discussões envolvendo os saberes e o processo formativo dos professores licenciados que atuam na EP.

\section{OS PROFESSORES LICENCIADOS E SUA FORMAÇÃO INICIAL}

Como esclarecido anteriormente, o objetivo desse texto é discorrer a respeito dos saberes docentes dos professores licenciados que trabalham na EP. Esses docentes são sujeitos que lecionam disciplinas de caráter geral, como por exemplo, Português, Matemática, Química, Física, Biologia, dentre outras. No Brasil, os professores destas áreas do conhecimento passam por uma formação inicial em cursos de licenciatura, o que possibilita legalmente seu trabalho em sala de aula na Educação Básica.

Imbernón (2009) esclarece que a formação inicial do professor deveria, dentre tantos quesitos, proporcionar pressupostos teórico-práticos para efetivar o processo de ensino e aprendizagem dos estudantes em sua plenitude. $O$ autor defende a ideia de uma formação inicial em que o professor apresente um sólido repertório de significados que proporcione sentido às pressões internas e externas socialmente construídas envolvidas no trabalho docente.

Pereira (2006) comenta que o professor, durante a sua formação inicial, precisa compreender o próprio processo de construção e produção do conhecimento escolar, entender as diferenças e semelhanças dos processos de produção do saber científico e do saber escolar, conhecer as características da cultura escolar, saber a história da ciência e a história do ensino da ciência com que trabalha e em que pontos elas se relacionam.

Tardif (2010) aborda essas características citadas por Pereira (2006) a partir da perspectiva dos saberes docentes, são eles: 1 ) da formação profissional (da ciência da educação e da ideologia pedagógica), referente ao conjunto de saberes transmitidos pelas instituições de formação de professores; 2) saberes disciplinares, relacionados com os saberes dos diversos campos do conhecimento, os saberes de que dispõe a nossa sociedade, tais como se encontram hoje 
integrados nas universidades, sob a forma de disciplinas (por exemplo, a Biologia); 3) saberes curriculares, associado aos discursos, objetivos, conteúdos e métodos, a partir dos quais a instituição escolar categoriza e apresenta os saberes sociais por ela definidos e selecionados como modelos de cultura erudita e de formação para a cultura erudita; 4) experienciais, vinculados ou baseados no trabalho cotidiano do professor e no conhecimento de seu meio, os quais brotam da experiência e são por ela validados.

Guimarães (2005) esclarece que a relação do professor com esses saberes não acontece, ou não deveria acontecer, de maneira fragmentada. O professor lida com saberes disciplinares numa perspectiva pedagógica e de construção de uma profissão. Portanto, com certa independência, recriando-os conforme o contexto, os recursos, sua história de vida, opções pessoais e as necessidades do aluno.

Entretanto, ainda se nota uma forte dicotomia entre teoria e prática na formação desses professores no Brasil e na aquisição e articulação desses saberes, principalmente para aqueles que atuam na EP. Pereira (2006) ressalta esse posicionamento ao lembrar da forte dicotomia entre teoria e prática, refletido também na separação entre ensino e pesquisa. Em outras palavras, os licenciandos em seu processo formativo inicial, são pouco estimulados a problematizar as questões inerentes ao seu futuro fazer enquanto professor, distanciando-se da perspectiva do professor pesquisador. Garcia (2007) esclarece que o educador pesquisador é aquele profissional que parte de questões relativas à sua prática com o objetivo de aprimorá-la. Pereira (2006) ainda ressalta a desvinculação das disciplinas de conteúdo e das pedagógicas, além do distanciamento existente entre a formação acadêmica e as questões impostas pela prática docente na escola.

Nesse sentido, percebe-se uma desvinculação, já na formação inicial, entre teoria e prática ou, em outras palavras, nota-se um distanciamento entre as discussões pedagógicas e a própria área específica e até mesmo com a realidade do cotidiano escolar no qual o professor estará envolvido. Tendo em vista esses fatores, o professor, ao ser incluído no processo de ensino e aprendizagem, possivelmente não desenvolva os saberes docentes necessários ao seu trabalho, posto que esses não foram constituídos de forma sólida na formação inicial.

Os cursos de formação inicial de professores no Brasil não estão, em sua maioria, possibilitando que os futuros profissionais do ensino articulem os saberes que competem aos professores, entretanto, Tardif $(2010$, p.13) lembra que esses saberes não se constituem apenas nesse momento inicial da carreira, pois "[...] os saberes profissionais dos professores são temporais, ou seja, são adquiridos através do tempo".

O autor continua discutindo esse ponto, ao afirmar que os saberes dos professores são integrados às práticas diárias de ensino, grande parte, sobredeterminadas por questões normativas, éticas e políticas. Ou seja, o ambiente no qual o professor encontra-se inserido, as relações estabelecidas por ele, a dinâmica política da escola e suas implicações na prática profissional, são fatores determinantes na constituição e reconstituição desses saberes (TARDIF, 2010).

Nessa perspectiva, os encaminhamentos ora citados, levam a um novo campo: o da formação continuada como processo crucial na constituição e articulação desses saberes docentes. Pereira (2006) compreende que essa formação deve estimular os professores a se apropriarem dos saberes que são internalizados, no quadro de uma autonomia contextualizada e interativa, que 
Ihes permita reconstruir os sentidos de sua ação profissional, rejeitando todos os dispositivos de supervisão e avaliação que se reduzam a controle sobre as suas práticas e sobre sua profissão.

Assim, o conjunto de saberes construídos pelos professores na formação inicial necessitam ser reconstruídos tomando como princípio o seu fazer docente, numa espécie de dinâmica mais ou menos organizada em que sua sistematização depende da própria inquietação e reflexão do professor enquanto sujeito do ensino, ou seja, o fazer docente deveria reconstruir esses saberes docentes iniciais a partir da reflexão.

A este saber, Pereira (2006) denomina "saber docente", que se constrói a partir do ingresso dos sujeitos no mundo do trabalho, nesse caso, reafirma-se a autenticidade de uma formação que se processa no contexto prático, na dinâmica do próprio processo de ensino, tomando como base a reflexão sobre seu fazer.

Como percebe-se, mesmo que brevemente, a formação do professor, seja ela inicial ou continuada, deveria ser permeada por diversos saberes, desde aqueles do conhecimento específico da ciência, por exemplo, da química, física, matemática ou biologia, aos conhecimentos pedagógicos inerentes ao fazer profissional docente. Entretanto, nota-se que existe um distanciamento dos professores na mobilização, sobretudo, articulada desses saberes, seja na formação inicial ou continuada.

Com relação à última, muitos professores são inseridos em contextos no qual possivelmente não apresentem um repertório de saberes para enfrentar os desafios e dilemas intrínsecos ao processo de ensino e aprendizagem, posto a discussão envolvendo a formação inicial desses profissionais. Possivelmente, isto venha a ser mais característico em campos de ensino sobre as quais existem poucas discussões a respeito nos cursos de formação de professores, como é o caso, por exemplo, da Educação Profissional (EP), da Educação de Jovens e Adultos (EJA) ou da educação a distância (EaD).

\section{OS SABERES DOCENTES DOS PROFESSORES QUE TRABALHAM NA EDUCAÇÃO PROFISSIONAL}

Como discutiu-se anteriormente, o professor é o principal agente envolvido no processo de ensino e aprendizagem dos alunos. Este, por sua vez, desde uma perspectiva sócio crítica, deveria além de problematizar os conhecimentos historicamente construídos, proporcionar aos estudantes os pressupostos para uma emancipação crítica nas dimensões cultural, social e política.

Posteriormente foi visto que os professores licenciados passam por uma formação inicial no qual deveria proporcionar um conjunto de saberes docentes que articulados, dão sentido ao seu fazer profissional. Entretanto, percebe-se que no Brasil os cursos de licenciatura ainda não preparam os professores nesse sentido, o que possivelmente comprometa a sua atuação posteriormente, sobretudo em modalidades/campo de trabalho específicos, como é o caso da EP.

No que tange à atuação e finalidade do trabalho do professor na EP, Machado (2008) comenta que este deveria ser um indivíduo da reflexão e da pesquisa, aberto ao trabalho coletivo e à ação crítica, extremamente comprometido com sua atualização permanente na área de formação específica e pedagógica, que tem plena compreensão das questões inerentes ao mundo do trabalho e das redes de relações que envolvem as modalidades, níveis e instâncias educacionais, 
além de um sólido conhecimento da sua profissão, bases tecnológicas e valores dos trabalho, bem como dos limites e possibilidades do seu fazer docente.

Para legitimar esse conjunto de pressupostos que norteiam o trabalho docente, é necessário que o professor mobilize determinados saberes específicos na EP. Moura (2008) e Araújo (2008) classificam esses saberes docentes intrínsecos ao trabalho do professor em 3 (três) tipologias, são elas: saberes técnicos, saberes pedagógicos e saberes da pesquisa. O primeiro, diz respeito aos conhecimentos específicos de cada área; o segundo, ao conhecimento do fazer docente e sua intencionalidade; e o terceiro assume uma dimensão de problematização sobre a prática do professor em sala de aula, abrindo espaço para possíveis ressignificações.

No que se refere ao saber pedagógico, Araújo (2008) considera que este deve ir além do caráter instrumental de técnicas de transmissão de conteúdos. O professor precisa tomar atitudes, forjadas a partir de um tipo de formação, que devem ser críticas, reflexivas e orientadas pela e para a responsabilidade social.

Com relação aos saberes do pesquisador, Araújo (2008) alerta para a necessidade de esses saberes ultrapassarem a dimensão dos projetos de pesquisa. $O$ autor acredita numa perspectiva de promover uma atitude de autonomia intelectual diante dos desafios da prática educativa do professor. Ou seja, a capacidade de o docente ressignificar sua prática cotidiana a partir do próprio contexto no qual se encontra inserido.

Acredita-se que este conjunto de saberes defendidos por Moura (2008) e Araújo (2008) coaduna com os princípios norteadores do papel do professor na EP e sua função social de formar cidadãos críticos, dentro de uma perspectiva de educação emancipatória, uma vez que os autores destacam os conhecimentos específicos de cada área como sendo primordiais, mas por outro lado, defendem a perspectiva pedagógica como algo inerente e indissociável do fazer docente nessa modalidade de ensino.

Silva Júnior e Garíglio (2014) buscaram discutir esses saberes a partir de um estudo com professores atuantes na $\mathrm{EP}^{1}$. Como resultados, encontraram os saberes dos professores ligados ao conhecimento técnico da área e à própria experiência profissional adquirida ao longo de sua carreira, que não necessariamente encontra-se inserida no contexto educacional. Ou seja, pode ter adquirido essa experiência na fábrica e/ou indústria. Além disto, os autores destacaram o saber adquirido no contato com outros docentes, no cotidiano da escola entre professores iniciantes e experientes.

Um outro grupo de sujeitos das pesquisas de Silva Júnior e Garíglio (2014) abordou os saberes pedagógicos como sendo essenciais ao fazer docente na EP. Entretanto, os autores ressaltaram que esta perspectiva aparece em segundo plano pelos docentes, numa posição mais baixa na hierarquização dos saberes necessários ao ensino na EP. Além disto, vale salientar que nos estudos de Oliveira (2008), os professores reduzem o saber pedagógico ao instrumentalismo, sem apresentar uma dimensão política de formação dos cidadãos, ou seja, desvinculado de um princípio de mudança social a partir da emancipação crítica dos estudantes.

\footnotetext{
${ }^{1} \mathrm{O}$ estudo dos autores surge de uma pesquisa de mestrado que teve como objeto de estudo os saberes de professores da educação profissional e tecnológica (EP) que lecionam disciplinas das áreas tecnológicas. Foram entrevistados dois professores experientes, vinculados a duas instituições de EP, uma pública e outra privada.
} 
Ao problematizar os saberes que norteiam o trabalho do professor na EP, é necessário compreender quem são esses sujeitos. Moura (2008) aponta a existência de 4 (quatro) perfis profissionais distintos, são eles: os profissionais não graduados; os bacharéis ou graduados em cursos superiores de tecnologia, mas não licenciados; os licenciados em disciplinas da educação básica e os ainda sem formação.

Em seu estudo, o autor discorre a respeito das especificidades de cada um desses segmentos. Entretanto, nesse artigo, direcionaremos nosso olhar para os professores licenciados que atuam em disciplinas da educação básica na EP. Moura (2008), ao discorrer sobre esse grupo, argumenta que os licenciados são formados para o exercício da docência no âmbito de uma ciência, ou seja, para atuar no ensino de Matemática, de Química, de Biologia etc.

Esses docentes, como discutido no tópico anterior, vivenciam uma formação inicial na qual deveriam construir um conjunto de conhecimento que articulados proporcionasse a efetivação do processo de ensino e aprendizagem. Dentre esses saberes, destacam-se os de caráter pedagógico. Souza e Nascimento (2013, p.422) comentam sobre a constituição desses conhecimentos nos cursos de licenciatura

A formação pedagógica, oferecida pelos cursos de licenciatura aos futuros docentes, fornece para estes os subsídios para que se materializem as propostas curriculares e se reflita sobre a relação professor/aluno, a qual não deverá se pautar apenas pela transmissão de conteúdos.

Por mais que esses professores apresentem um conjunto de saberes pedagógicos na sua formação inicial, Moura (2008) lembra que é diferente trabalhar, mesmo na disciplina específica, em cursos cujo fim é a formação técnica de nível médio, principalmente, o ensino médio integrado à educação profissional. Da mesma forma, Silva Júnior e Garíglio (2014, p.889) acreditam que "ensinar na EP e na educação regular não é fazer a mesma coisa, ou melhor, não é objeto de igual consideração". Araújo (2008 p.10) complementa esses argumentos, afirmando que "a formação didático-pedagógica dos cursos de licenciatura não prepara o docente para enfrentar uma sala de aula de instituição de educação profissional". Ou seja, a EP é permeada por singularidades características do fazer docente que a diferencia da educação regular ou propedêutica. Essas singularidades demandam metodologias específicas, o que exige do professor saberes docentes outros, muitas vezes não aprendidos em sua formação inicial.

Sendo assim, os autores discorrem a respeito das especificidades do trabalho docente no campo da EP. Mesmo apresentando uma formação inicial que contribua na constituição dos saberes pedagógicos, de acordo com os autores supracitados, os professores licenciados atuantes na EP precisam dar continuidade a sua formação, tendo em vista as especificidades dos objetivos do ensino técnico e, sobretudo, do ensino médio integrado.

Como alternativa para esse cenário, defende-se aqui a realização de discussões e sistematização de conhecimentos acerca do mundo do trabalho, EP e ensino médio integrado já nos cursos de formação inicial de professores, tendo em vista que esses futuros professores são habilitados também a realizar seu trabalho na EP. Por isso é necessário repensar a própria formação inicial do professor, tendo em vista sua intencionalidade e especificidades.

Já no que tange à formação continuada, Moura (2008) ressalta a necessidade de aproximar esses professores das relações entre trabalho e educação e ao vasto campo da EP no sentido de 
estabelecer as conexões entre essas disciplinas e a formação profissional específica, contribuindo para a integração entre trabalho, ciência, tecnologia e cultura. Isso é fundamental, pois os cursos de licenciatura, em geral, não incluem em seus currículos estudos aprofundados sobre esse campo e menos ainda sobre a sua relação com o ensino médio.

Para esse cenário, o autor compreende a necessidade de formação em pós-graduação lato sensu. Entretanto, chama a atenção para o fato de que essa formação deve apresentar características específicas no intuito de aproximar os professores da educação profissional aos conhecimentos da área da educação em geral e, igualmente, de aproximar os licenciados às questões do mundo do trabalho e das relações entre suas disciplinas e as denominadas disciplinas profissionalizantes.

Além disto, Moura (2008) chama a atenção para a necessidade de pensar essa formação continuada a partir do próprio contexto escolar no qual os professores dessas disciplinas estão inseridos, tendo em vista que os saberes experienciais são fundamentais na ressignificação dos conhecimentos adquiridos durante a formação inicial.

Logo, seja na formação inicial ou na formação continuada, os professores licenciados atuantes na EP necessitam de saberes docentes voltados para as questões inerentes a este campo de ensino, seja o referencial envolvendo o mundo do trabalho, as discussões do ensino médio integrado, bem como a intencionalidade da emancipação social dos estudantes a partir da problematização das demandas do regime econômico posto na atualidade.

\section{CONSIDERAÇÕES}

Situando no contexto das discussões envolvendo os saberes docentes que permeiam o fazer dos professores de Biologia na EP, essa produção surgiu como parte das inquietações iniciais a respeito dessa problemática. Posto isto, objetivou-se discutir a respeito da formação de professores na EP e os saberes mobilizados pelos docentes em seu fazer cotidiano.

As discussões aqui apresentadas mostraram um conjunto de saberes docentes que permeia o fazer docente dos professores atuantes na EP: os saberes técnicos, pedagógicos e da pesquisa, cada um apresentando suas especificidades. No que se refere ao grupo de professores licenciados, percebe-se a necessidade de um aprofundamento nas questões específicas da EP, como por exemplo o trabalho pensado a partir do seu sentido ontológico e a necessidade de uma reflexão por parte do docente com relação aos pressupostos da EP integrada à educação propedêutica, para que assim, esses professores possam efetivar o seu processo de ensino e aprendizagem numa perspectiva que coaduna com os princípios formativos da educação emancipatória.

Logo, defende-se uma ressignificação da formação docente para atuar na EP, uma vez que esta apresenta aspectos teóricos, práticos e de intencionalidade formativa muito específica e, ao mesmo tempo, abrangente, principalmente quando se pensa em formação integral. No que se refere aos professores licenciandos que atuam nessa modalidade de ensino, acredita-se que os cursos de pós-graduação lato sensu voltados para o contexto teórico prático da formação humana integral e suas diretrizes políticas aparecem como uma opção a ser pensada. 


\section{REFERÊNCIAS}

1. ALMEIDA, Jorge Miranda. LACERDA, Fabrício Santana. Filosofia e Educação em Tempos de Crise: Por uma educação emancipadora. Disponível em: http://www.periodicosele tronicos.ufma.br/index.php/revistahumus/article/viewFile/3370/1399. Acesso em: 05/06/2015.

2. ANTUNES, Ricardo Luis Coltro. Os sentidos do Trabalho: Ensaio sobre a afirmação e a negação do trabalho. 2ำ ed. São Paulo, SP. Boitempo, 2009.

3. ARAÚJO, Ronaldo Marcos de Lima. Formação de docentes para a educação profissional e Tecnológica: por uma pedagogia integradora da educação profissional. Trabalho \& Educação. Vol. 7. no 2.mai-/ago, 2008.

4. GARCIA, Vera Clotilde Vanzetto. Fundamentação teórica para as perguntas primárias: $\mathrm{O}$ que é matemática? Por que ensinar? Como se ensina e como se aprende?. Educação, Porto Alegre, v. 32, n. 2, p.176-185, maio 2009.

5. GUIMARÃES, Valter Soares. Os saberes dos professores: Ponto de partida para a formação continuada. 2005. Disponível em: <http://www.tvbrasil.org.br/fotos/salto/series/150934 FormacaoCProf.pdf>. Acesso em: 09 abr. 14.

6. IMBERNÓN, Francisco. Formação docente e profissional: formar-se para a mudança e a incerteza. 7a ed. São Paulo, Cortez, 2009.

7. MACHADO, Lucia Regina de Souza. Diferenciais inovadores na formação de professores para a educação profissional.Revista Brasileira da Educação Profissional e Tecnológica, Ministério da Educação, Secretaria de Educação Profissional e Tecnológica, v. 1, n. 1, jun. 2008. Brasília: MEC, SETEC, 2008.

8. MOURA, Dante Henrique. A formação de docentes para a educação profissional e tecnológica. Rrevista Brasileira da Educação Profissional e Tecnológica, Brasília, v. 1, n. 1, p.23-38, jun,2008.

9. OLIVEIRA. Maria Rita Neto Sales. Formação e profissionalização dos professores do ensino técnico. Educação e Tecnologia, Belo Horizonte, v.11, n.2, p.3-9, jul./dez. 2006.

10. PEREIRA, Júlio Emílio Diniz. Debates e pesquisas no Brasil sobre a formação docente. In: PEREIRA, Júlio Emílio Diniz. Formação de professores: pesquisas, representações e poder. 2a ed. Belo Horizonte: Autêntica, 2006.

11. SILVA JÚNIOR, Geraldo Silvestre; GARIGLIO, José Ângelo. Saberes da docência de professores da educação profissional. Revista Brasileira de Educação, São Paulo, v. 19, n. 59, p.871-892, jun, 2014.

12. SOUZA, Francisco das Chagas Silva e; NASCIMENTO, Viviane Souza de Oliveira. Bacharéis Professores: um perfil docente em expansão na rede federal de educação, ciência e tecnológica. In: MOURA, Dante Henrique (Org.). Produção de Conhecimento, Políticas Públicas: e Formação docente em Educação Profissional. Campinas: Mercado de Letras, 2013. p. 409-435.

13. TARDIF, Maurice. Saberes docentes e formação profissional. 11aㅡ ed. Petrópolis, RJ: Vozes, 2010. 